\title{
SISTEM PENCARIAN LOKASI ANJUNGAN TUNAI MANDIRI (ATM) MEMANFAATKAN GOOGLE MAP UNTUK HANDPHONE ANDROID YANG MEMILIKI FASILITAS GLOBAL POSITIONING SYSTEM (GPS) STUDI KASUS BPD DIY
}

\author{
Hendra Nurrahmanto, Sumarsono, Maya Suhayati \\ Jurusan Teknik Informatika \\ Sekolah Tinggi Teknologi Adisutjipto Yogyakarta \\ informatika@stta.ac.id
}

\begin{abstract}
The denser the activity of modern lifesquad, made in every case the limitations of everyday life. As an example when the transactions at the Bank, this can be facilitated by the presenc of ATM. Meanwhile, many users do not know ATM locations, especially when users from the other town so it is considered sufficient applied for search ATM locations. The method used in this study for mapping utilizing google map. In this application user can search for ATM locations easily as determined by the position of the user is located. With GPS devices available on the smartphone can find locations user smartphone and ATM locations. ATM search applications can be used when the smartphone is connected to internet.
\end{abstract}

Keyword: GPS, Locations Search ATM, Android

\section{Pendahuluan}

Handphone saat ini sudah menjadi bagian dari gaya hidup masyarakat Indonesia. Sebagai alat komunikasi, handphone telah menjadi sebuah kebutuhan pokok bagi komunikasi masyarakat. Perkembangan teknologinya pun semakin cepat. Handphone sebagai sebuah media komunikasi dalam perkembangan teknologinya telah menciptakan sebuah konvergensi teknologi digital, sehingga dapat merangkap berbagai fungsi komunikasi, Internet, multimedia dan entertainment sekaligus. Hal ini tentunya memberikan kemudahan sekaligus nilai tambah bagi masyarakat pemakainya, khususnya pengguna handphone android.

Android merupakan sebuah sistem operasi yang terdapat pada handphone, Android dibangun di atas kernel Linux 2.6. Namun secara keseluruhan android bukanlah linux, karena dalam android tidak terdapat paket standar yang dimiliki oleh linux lainnya.

Di dalam handphone android kini terpasang aplikasi GPS (Global Positioning System). GPS merupakan suatu perangkat pada handphone yang berfungsi untuk menentukan posisi di permukaan bumi dengan bantuan sinkronisasi sinyal satelit. Teknologi GPS dapat memudahkan pengguna handphone sehingga tidak tersesat saat bepergian karena dapat menginstal aplikasi peta di dalamnya. 
Mengingat semakin padatnya aktifitas di kehidupan zaman modern ini, maka tidak dipungkiri lagi membuat keterbatasan dalam setiap hal kehidupan sehari-hari. Sebagai contoh ketika ada keterbatasan waktu transaksi di bank untuk mengambil uang maupun melakukan transfer uang, hal ini dapat dimudahkan dengan adanya ATM (Anjungan Tunai Mandiri). Sementara itu banyak pengguna ATM yang tidak mengetahui lokasi-lokasi ATM khususnya ketika pengguna berada diluar kota sehingga dirasa cukup diterapkan dalam pencarian lokasi ATM.

Berdasarkan permasalahan tersebut di atas, maka penulis akan mencoba membuat suatu aplikasi pencarian mesin ATM terdekat dengan memanfaatkan GPS pada handphone yang bersistem operasi android. Dengan sistem informasi geografis pencarian ATM terdekat menjadi lebih mudah.

\section{Landasan Teori}

\subsection{Sistem Navigasi GPS (Global Positioning System)}

GPS (Global Positioning System) adalah sistem satelit navigasi dan penentuan posisi yang dimiliki dan dikelola oleh Amerika Serikat. Sistem ini didesain untuk memberikan posisi dan kecepatan tiga-dimensi serta informasi mengenai waktu, secara kontinyu di seluruh dunia tanpa bergantung waktu dan cuaca, bagi banyak orang secara simultan. Saat ini GPS sudah banyak digunakan orang di seluruh dunia dalam berbagai bidang aplikasi yang menuntut informasi tentang posisi, kecepatan, percepatan ataupun waktu yang teliti. GPS dapat memberikan informasi posisi dengan ketelitian bervariasi dari beberapa millimeter (orde nol) sampai dengan puluhan meter.

\subsection{Google Map}

Google Maps adalah aplikasi Maps sederhana yang versinya lebih tinggi di Android dibanding di Blackberry. Bila memakai aplikasi berbayar, maka Google maps jelas masih kalah jauh, tetapi untuk aplikasi standard tak berbayar, sebenarnya sudah lebih dari cukup untuk dimanfaatkan. Untuk versi terbarunya saat ini sudah rilis google maps 5.10. Bahkan kini google maps sudah support 3D views tetapi di Indonesia belum bisa menggunakan $3 D$ views. Google $3 D$ views baru hanya bisa digunakan di Negara-negara seperti Amerika, Jepang, dan negara-negara eropa.

\subsection{Bank BPD DIY}

Saat ini Bank BPD DIY telah memiliki 45 terminal ATM yang tersebar di seluruh DIY.

ATM Bank BPD DIY tergabung dalam jaringan ATM BERSAMA dimana pemegang kartu ATM Bank BPD DIY dapat melakukan transaksi di seluruh terminal ATM yang berlogo ATM BERSAMA dengan jumlah terminal lebih dari 10.000 diseluruh Indonesia.

Sejak tanggal 15 November 2006 Bank BPD DIY telah mengimplementasikan fitur Malaysian Electronic Payment System (MEPS). Fitur MEPS merupakan kerjasama interkoneksi antara Artajasa sebagai penyelenggara ATM BERSAMA dengan MEPS sebagai penyelenggara jaringan BANKCARD di Malaysia.

Dengan adanya kerjasama ini maka pemegang kartu ATM BANK BPD DIY dapat melakukan transaksi di terminal anggota BANKCARD di Malaysia dan 
sebaliknya pemegang kartu berlogo BANKCARD dapat bertransaksi di terminal ATM Bank BPD DIY.

Fitur-fitur ATM yang tersedia adalah:

1. Penarikan Tunai

2. Cek Saldo

3. Penggantian PIN

4. Transfer Antar Rekening dan Antar Bank

5. Pembayaran tagihan Telepon

6. Pembayaran tagihan Internet Speedy

7. Pembayaran tagihan Telkomsel kartu HALO

8. Pembayaran tagihan Indosat Matrix

9. Pembayaran tagihan StarOne Postpaid

10. Pembelian Tiket Mandala Airlines

11. Pembelian Tiket Kereta Api

12. Pembelian Pulsa Simpati dan Kartu As

13. Pembelian Pulsa Indosat Mentari dan IM3

14. Pembelian Pulsa StarOne Prepaid

15. Pembayaran biaya akademik UNY

\section{Perancangan Sistem}

\subsection{Analisa Awal}

Bagi masyarakat biasa didalam pelaksanaan pencarian ATM terdekat haruslah hafal terlebih dahulu letak-letak ATM yang ada serta hafal juga rute jalanan untuk daerah Kota Yogyakarta. Dengan menggunakan teknologi mobile (handphone) dengan sistem operasi android maka dengan ditambahkan aplikasi pencarian ATM maka user dimudahkan dalam mencari letak ATM terdekat dari posisinya. Dengan pemanfaatan aplikasi ini wisatawan dari luar Yogyakarta pun dimudahkan dalam pencarian ATM meskipun belum pernah ke Yogyakarta.

Aplikasi ini selalu berkembang sesuai aplikasi yang kontemporer dengan developer aplication mobile program dan aplikasi tersebut dapat dinikmati melalui android phone market. Didalam android phone market memiliki aplikasi yang bersifat berbayar maupun free sehingga pengguna mobile smarthphone dapat menikmati teknologi aplikasi yang bervariatif.

Dalam menggunakan aplikasi ini handphone yang digunakan harus memiliki perangkat GPS (Global Positioning System). Dalam menentukan letak ATM-ATM berdasarkan pada peta google menggunakan koordinat latitude dan longitude. Adapun konsep aplikasi pencarian ATM adalah seperti yang terlihat pada gambar 1 . 


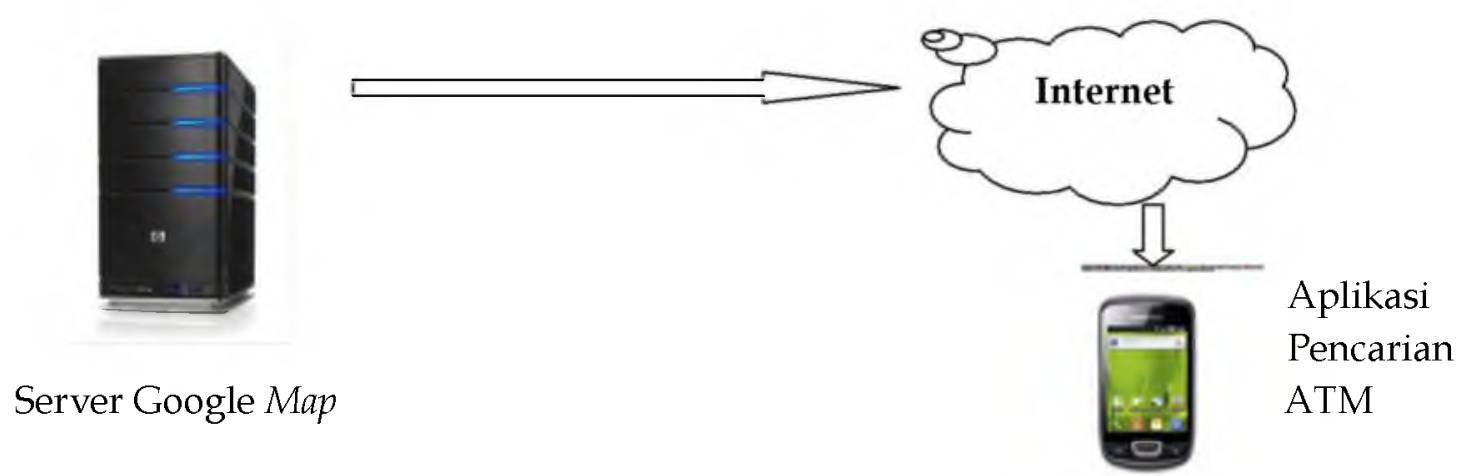

Gambar 1 Konsep Aplikasi Pencarian ATM

\subsection{Diagram Use Case}

Kebutuhan user dalam pencarian ATM adalah jarak terdekat dari posisi user. Hasil yang dicapai pada tahap ini adalah sebuah diagram use-case pada gambar 2.

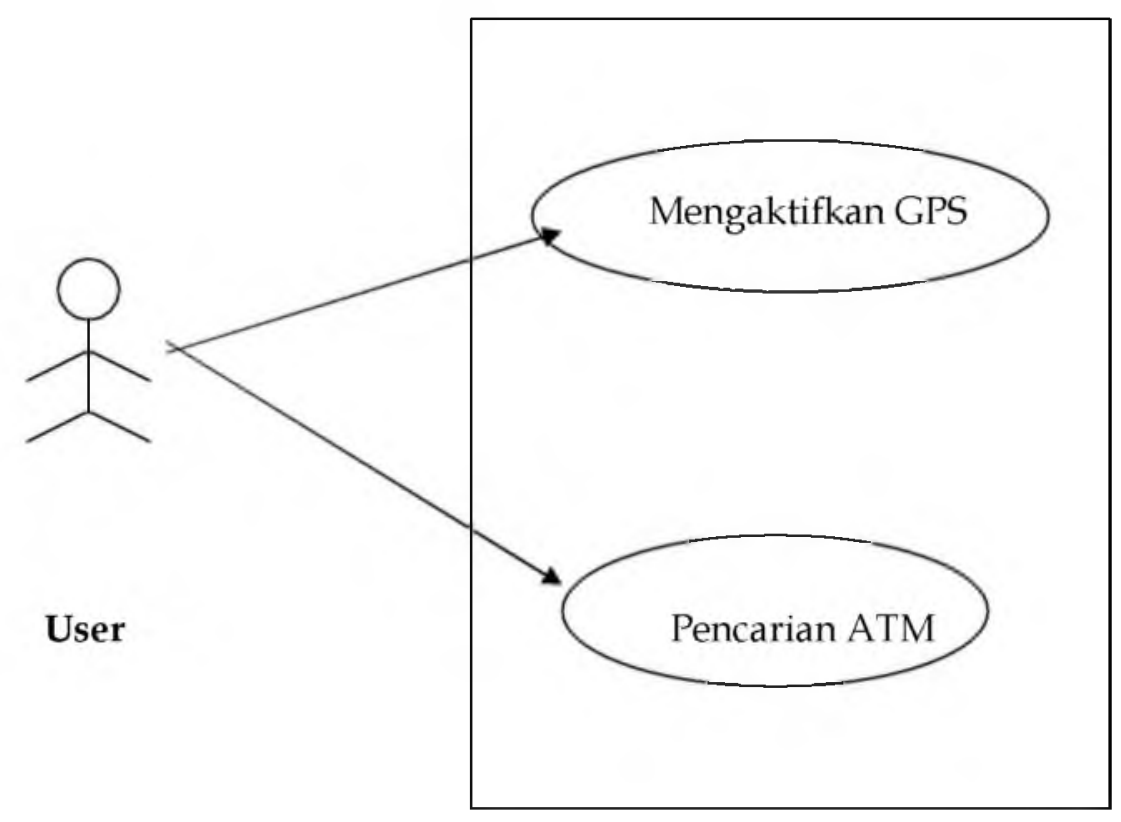

Gambar 2 Diagram Use Case

Pada diagram use case yang terdapat di gambar 3.2 dijelaskan bahwa pada saat menggunakan aplikasi pencarian ATM ini user terlebih dahulu mengaktifkan GPS yang ada di smartphone setelah itu baru bisa mencari lokasi ATM.

\subsection{Diagram Kelas}

Diagram kelas yang terdapat pada aplikasi yang dirancang dengan menerangkan relasi-relasi yang terjadi pada kelas seperti dependency dan Association. Perincian kelas ditampilkan dalam diagram ditunjukkan pada gambar 3. 


\begin{tabular}{|l|}
\hline Lokasi \\
\hline Attributes \\
\hline $\begin{array}{l}\text { Operations } \\
\text { Public } \\
\text { Lokasi() }\end{array}$ \\
\hline
\end{tabular}

\begin{tabular}{|l|}
\hline $\begin{array}{l}\text { MyItemizedOver } \\
\text { lay }\end{array}$ \\
\hline Attributes \\
\hline $\begin{array}{l}\text { Operations } \\
\text { Public } \\
\text { MyItemizedOverl } \\
\text { ay () }\end{array}$ \\
\hline
\end{tabular}

\begin{tabular}{|c|}
\hline $\begin{array}{l}\text { TunjukLokasiBerak } \\
\text { si }\end{array}$ \\
\hline Attributes \\
\hline $\begin{array}{l}\text { Operations } \\
\text { Public } \\
\text { TunjukLokasiBeraksi } \\
()\end{array}$ \\
\hline
\end{tabular}

Gambar 3 Diagram kelas

Adapun tabel deskripsi kelas seperti terlihat pada tabel 1

Tabel 1 Deskripsi Kelas

\begin{tabular}{|l|l|}
\hline Kelas & Deskripsi \\
\hline Kelas Lokasi & $\begin{array}{l}\text { Kelas ini berfungsi sebagai penyimpanan } \\
\text { data lokasi bangunan, pada project ini adalah } \\
\text { ATM }\end{array}$ \\
\hline Kelas MyItemzedOverlay & $\begin{array}{l}\text { Kelas ini berfungsi sebagai penghubung } \\
\text { antara kelas Lokasi dan kelas } \\
\text { TunjukLokasiOverlay }\end{array}$ \\
\hline Kelas TunjukLokasiBeraksi & $\begin{array}{l}\text { Kelas ini berfungsi sebagai penentuan letak } \\
\text { lokasi ATM dan GPS berdasarkan koordinat } \\
\text { latitude dan longitude }\end{array}$ \\
\hline
\end{tabular}




\section{Implementasi}

\subsection{Simbol-simbol Aplikasi}

Ada beberapa simbol-simbol dalam aplikasi pencarian ATM. Berikut adalah arti dari symbol-simbol tersebut. Seperti terlihat pada gambar 4 .

$=$ Simbol GPS

\section{BANK (O) BPD DIY}

$=$ Simbol ATM Bank BPD DIY

Gambar 4 Simbol Aplikasi

\subsection{Tampilan Aplikasi}

Pada tampilan aplikasi ini akan dijelaskan fitur-fitur aplikasi dan cara menggunakan aplikasi pencarian ATM ini. Pada gambar 5 adalah tampilan awal ketika program pencarian ATM dibuka.

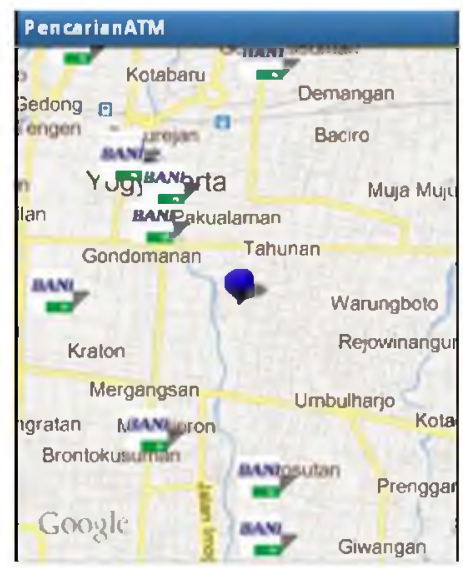

Gambar 5 Tampilan Awal Program

\subsection{Pengujian Sistem}

Pengujian sistem dilakukan ketika sedang berjalan dengan sepeda motor, lalu lokasi GPS pada aplikasi ikut bergerak sesuai dengan posisi sesungguhnya dimana lokasi berada. Ketika di uji di dalam mobil yang jendelanya tertutup rapat juga hasilnya sama seprti ketika menggunakan sepeda motor ketika mobil berjalan maka gambar lokasi GPS juga ikut jalan sesuai dengan posisi lokasi mobil.

Jadi aplikasi pencarian ATM ini berjalan berdasarkan koneksi internet, apabila di lokasi sinyalnya bagus maka koneksi internet juga otomatis bagus dan aplikasinya pun berjalan dengan lancar. Tapi apabila sinyalnya lemah maka koneksi internet juga akan lemah dan aplikasinya akan berjalan lambat atau bahkan tidak bisa berjalan.

Aplikasi pencarian ATM ini hanya support pada smartphone android. Karena file eksekusinya adalah *.apk dan aplikasi ini hanya bisa berjalan pada handphone bersistem operasi android. Aplikasi ini sudah di uji coba pada handphone bersistem 
operasi android, blacberry dan symbian.

\section{Kesimpulan}

Beberapa kesimpulan yang dapat diambil dari penyusunan skripsi ini antara lain:

1. Aplikasi pencarian ATM ini dapat berjalan apabila ada koneksi internet, sehingga lancar atau tidaknya program ini tergantung pada sinyal yang ada. Dengan aplikasi ini juga user bisa mencari ATM terdekat dari lokasi user berada.

2. Aplikasi pencarian ATM ini pada pemetaannya memanfaatkan google map sebagai servernya. Dalam menentukan letak lokasi ATM pada peta haruslah survei ke tempat lokasi ATM untuk menemukan koordinat latitude dan longitude.

3. Program pencarian ATM hanya bisa dijalankan di handphone bersistem operasi android, sedangkan handphone selain android tidak bisa beroperasi karena file eksekusinya berbeda dengan handphone android.

\section{Saran}

Dalam analisis sistem dapat diketahui cara kerja sistem sehingga di dapatkan saran-saran untuk pengembangan aplikasi ini selanjutnya. Saran-saran tersebut antara lain :

1. Aplikasi ini dikembangkan lagi dengan ditambahkan fitur update ATM.

2. Aplikasi ini dikembangkan lagi dengan memperbanyak ATM Bank yang ada di Indonesia baik Bank swasta maupun Bank milik pemerintah.

3. Aplikasi ini dikembangkan lagi supaya dapat diakses dari handphone selain android.

\section{Daftar Pustaka}

Al-Bahra, Ladjamudin. 2005. Analisis dan Desain Sistem Informasi. Graha Ilmu : Yogyakarta

Irwansyah, Edy, dkk. 2011. Pengembangan Sistem Informasi Geografis (SIG) Pada Platform Google Untuk Penanggulangan Kebakaran di Jakarta Selatan. Jurnal. Universitas Bina Nusantara. Jakarta.

Nugroho Adi. 2009. Rekayasa Perangkat Lunak Menggunakan UML dan Java. Andi : Yogyakarta.

Prahasta Eddy. 2005. Konsep-konsep Dasar Sistem Informasi Geografis. Informatika : Bandung.

Pressman, S, Roger. 2002. Rekayasa Perangkat Lunak. Andi : Yogyakarta

Safaat, Nazruddin. 2011. Android Pemrograman Aplikasi Mobile Smartphone dan Tablet PC Berbasis Android. Informatika : Bandung.

Suarga. 2006. Algoritma Pemrograman. Andi : Yogyakarta

Widjaja, Damar, dkk. 2009. Akuisisi Data GPS (Global Positioning System) Untuk Pemantauan Jaringan GSM (Global System for Mobile Communications). Jurnal. Universitas Sanata Dharma. Yogyakarta.

http:/ / www.avriqzramadhan.wordpress.com/tag/konsep-manajemen-proses-di-sistemoperasi-android-3-0-honeycomb/. Diakses tanggal 11 juni 2011 Pk1. 17.00

http:/ / www.bpddiy.co.id/. Diakses tanggal 09 November 2011 Pkl. 07.00.

http://www.ekoshp.com/2011/04/manfaatkan-google-maps-android/. Diakses tanggal 09

November 2011 Pkl. 07.00 
http:/ / www.fahripeblog.wordpress.com/2009/08/12/garis-lintang-dan-garis-bujur/. Diakses tanggal 09 November 2011 Pkl. 07.00.

http://www.gaulwahyu.wordpress.com/2008/10/16/pengertian-gps/. Diakses tanggal 09 November 2011 Pkl. 07.00

http://www.ikc.depsos.go.id/umum/yanti-uml.php. Diakses tanggal 20 Juni 2011 Pk 